\title{
CHAPTER 8 DEVELOPING AND MAINTAINING AN EFFECTIVE LEARNING ENVIRONMENT
}

\section{Kerry Whitehouse, Lerverne Barber and Vanessa Jones}

\section{INTRODUCTION}

Developing and maintaining an effective learning environment in your lessons supports other aspects of your teaching by providing the best possible conditions to promote and support each pupil's learning, progress and achievement and to prevent misbehaviour. This chapter is designed to help you develop and maintain an effective learning environment for effective pupil learning.

Developing and maintaining an effective learning environment which promotes positive behaviour does not happen by chance. There are a multitude of factors to consider; in this chapter these are organised around the A.R.T. of positive behaviour management. Awareness of: yourself (selfawareness) in the way you present yourself; the lesson climate; why pupils misbehave. Relationships: knowing pupils as individuals; communicating effectively; promoting positive interpersonal relationships between teacher and pupils, and between pupils; and understanding the impact of praise and rewards on behaviour and the learning environment. Thoughtful planning to use time effectively, ensuring all pupils are challenged and can achieve the intended learning, and the management of the working space. The chapter is structured using the A.R.T. model.

Your ability to understand how to create an effective learning environment and promote positive behaviour develops as you gain experience and practise a variety of approaches. These are strengthened as you get to know your pupils and develop supportive and respectful relationships.

The United Kingdom government pledge to support teachers and head teachers in promoting positive behaviour and sanctioning behaviours which are unacceptable, means that schools must ensure that they have a strong behaviour policy, which includes advice on the use of rewards and sanctions which are applied consistently (Department for Education (DfE), 2014d). It is important that you understand and are aware of the school behaviour policy as a starting point when you first begin school placement and later as you start to teach. School policies however are a small part of the big picture; effective and positive learning environments go much deeper.

Effective non-verbal communication is an important factor in developing an effective learning environment. In developing aspects of your teaching designed to develop an effective learning environment, you will use some of the skills identified in other chapters in this book. You should therefore refer to other chapters, where appropriate.

\section{OBJECTIVES}

Accepted draft 
At the end of this chapter you should be able to:

- understand the importance of creating an effective learning environment and a positive lesson climate;

- appreciate some aspects of self-presentation that are important to PE teachers;

- understand the importance of building positive and respectful relationships with pupils;

- understand the importance of purposefulness in a lesson;

- appreciate how to use time and space effectively to engage all pupils in a stimulating learning environment;

- understand the role of an effective learning environment in promoting positive behaviour as a means of preventing misbehaviour;

- understand the importance of non-verbal communication in developing and maintaining an effective learning environment.

Check the requirements of your initial teacher education (ITE) to see which relate to this chapter.

\section{A.R.T: AWARENESS}

This section looks at awareness of: yourself (self-awareness) in terms of the way you present yourself; the lesson climate; and why pupils misbehave, including the importance of consistency of pupil expectation.

\section{Self-awareness: How you present yourself and how you are perceived by the pupils}

Task 8.1 asks you to identify the message you think the teacher is sending to pupils through the examples of good practice identified.

\section{Task 8.1 What message is the teacher sending?}

Read the statements below and identify what messages you think the PE teacher is sending through these examples of good practice.

- The teacher arrives at the lesson before the pupils in order to meet them outside the changing room;

- The practical space is set up ready for the lesson when the pupils enter;

- The teacher greets all of the pupils by name as they enter the space;

- The teacher dresses appropriately for the type of activity being taught e.g. bare feet for gymnastics/dance; smart clothes for classroom lessons;

- The changing rooms and indoor working spaces are well maintained and have resources on the Accepted draft 
walls to support and enhance learning;

- Pupils are included in other aspects of PE when they are unable to take part practically e.g. as coach, performance analyst, choreographer, etc.

- Sporting achievements are recognised and celebrated via the appropriate channels, e.g. on the walls of the PE department; during assemblies; in newsletters; on the web.

What message do you communicate to the pupils in each of these scenarios? How does this influence their perception of you? Are the aspects of good practice a true reflection of the teacher you aim to be? Discuss your responses with your tutor or another student teacher. Store your findings in your professional development portfolio (PDP) for reference later.

All the statements above relate to the teacher being well prepared for the lesson and creating a positive working environment for the pupils. These are attributes of an effective teacher. Task 8.2 asks you to consider other attributes of an effective PE teacher.

\section{Task 8.2 Key words to describe an effective PE teacher}

Write down twelve to fifteen adjectives or phrases you might use to describe an effective PE teacher, for example, 'patient', 'well organised'. Underline all those that refer to how you might present yourself as a PE teacher. Compare your list with that of another student teacher doing the same task.

Store this information in your PDP.

Although teacher attributes are related to the personality of each individual, it would be surprising if your list of adjectives or phrases to describe an effective PE teacher differed radically from that of another student teacher doing the same task. Such is the particular nature of the subject of PE that to be successful you need to exhibit key attributes or characteristics. These enable you to gain the respect of pupils, motivate them to work and to promote the learning of each individual pupil. In turn these promote positive behaviour.

As an enthusiastic and committed teacher you plan and prepare each lesson thoroughly, identifying obtainable, appropriate and challenging but achievable intended learning outcomes (ILOs) for pupils and differentiating learning tasks to accommodate the needs of each individual pupil, arrive early for the lesson, provide a quick pace to the lesson and do not allow minor interruptions to interfere with the lesson. You have a positive approach and teaching style, smile a lot, praise pupils for effort or performance, give specific, positive feedback whenever possible and encourage pupils to achieve the ILOs, therefore developing a positive lesson climate. Further, you dress and act as though you are enthusiastic about, and participate in, physical activity yourself. It is also an advantage to be a positive role model in your skilful execution of movement skills, and it is certainly the case that teacher Accepted draft 
demonstrations can help to inspire and enthuse pupils. There are three fundamental aspects of effective teacher self-presentation. These are discussed below.

First, a PE teacher needs to be confident, authoritative and clearly in control of the situation. These self-presentational attributes are necessary because you frequently work in a large space, at some distance from many of the pupils and in an environment that may contain safety hazards (see also Chapter 12). To retain your authority you must convey clearly an assured and business-like selfpresentation. Elements that contribute to the teacher's authority have been identified by Kyriacou (2009, p.103) as 'Subject knowledge; interest in and enthusiasm for the subject; and, the ability to set up effective learning experiences.' Appropriate and smart clothing are also essential. You are in part an organiser and a safety manager and your presentation must reinforce these roles.

Second, a PE teacher needs to be energetic and enthusiastic. While all teachers have to engage and interest pupils, you have to motivate pupils to expend considerable effort to gain most from the lesson. A lethargic teacher is hardly likely to have a dynamic and determined class. In everything you do, you need to be alert, lively and encouraging. Do you convey to your pupils your enthusiasm for your subject content, and for them and their learning, improved performances and expenditure of effort? How do you accomplish this?

Although it is difficult to define precisely how enthusiasm is shown, as this is unique to each of you, it is important that as an enthusiastic and committed physical educationalist you convey your enthusiasm to the pupils, therefore enthuse and motivate them to participate. However, it is worth remembering that enthusiastic teachers vary their voice, gestures, expressions; move around the teaching space; and maintain a quick pace to the lesson that involves high levels of interaction with pupils.

Third, a PE teacher's self-presentation needs to convey more than an authoritarian, able sports person. The movement skills that are often the focus of the lesson are performed by the pupils for all to see, and so there is a danger of self-consciousness, as the pupil's very selves, their bodies, are the subjects of observation and evaluation. The work in PE is therefore of a very personal nature and you need self-presentational skills that demonstrate a dimension of understanding and sensitivity. Furthermore, you need to convey to the pupils that you are approachable, sympathetic and caring. You should show both verbally and non-verbally, that concern for pupils and their respective efforts are at the heart of the lesson.

Caring is revealed both in the interaction between teachers and pupils and between pupils. A caring pedagogy (Noddings, 1992, cited in Siedentop and Tannehill, 2000) embraces pupils’ personal and social growth and achievement to try to 'create a synergy between the learning goals and social goals of physical education' (Siedentop and Tannehill, 2000, p.106). Thus, teachers care that pupils learn and improve. It is based on the belief that if pupils feel respected and accepted by the teacher and their peers they are more likely to apply themselves to their learning. A caring pedagogy includes: 
- Pupils who are supportive, responsible, accountable, cooperative, trusting, empowered, identify with the class, and committed to fairness and caring.

- Learning communities which have boundaries, persist over time, share common goals, value cooperative practices, identify with community symbols and rituals, and are committed to fairness and caring.

- Strategies for sustaining fairness and caring, such as collaboratively developed class procedures and discipline codes, class meetings to solve problems and develop class norms, challenging learning activities emphasising respect, opportunities to know one another, and willingness to deal with values in the curriculum.

- Investment in the development of pupils and sustaining conditions within which pupils protect the rights and interests of classmates.

- Teacher practices such as helping, valuing pupils, treating pupils respectfully, being tolerant, encouraging and supporting which are viewed by pupils as caring.

- Caring teachers who plan challenging and significant activities and help pupils achieve important outcomes.

- Caring teachers with skills and knowledge that relate to diversity issues in pedagogy and in the content being taught.

(adapted from Siedentop and Tannehill, 2000, p.115)

Your self-presentation should at all times demonstrate your professionalism and genuine concern for each individual pupil. Units 1.2 (Allen and Toplis) and 3.1 (Zwozdiak-Myers and Capel) in Capel, Leask and Turner (2013) cover aspects of self-presentation. Task 8.3 focuses on self-presentation.

\section{Task 8.3 Effective self-presentation}

Return to Task 8.2 and compare the three aspects of self-presentation identified above (confident, authoritative and clearly in control of the situation; energetic and enthusiastic; understanding and sensitive) with your list and those aspects you underlined. Discuss with another student teacher how far you agree with the priority given to these three. Set yourself the challenge to convey these three attributes during your next week of teaching. Ask your tutor to give you feedback on your mastery of each. Record your success, or otherwise, in your PDP.

It is worth taking time to check aspects of your non-verbal communication in relation to your selfpresentation, for example, use of your voice (see also chapter 5), the clothes you wear, confidence and your movement in a lesson. You might also want to check other aspects of how you present yourself; for example, whether you have any habits or mannerisms such as the overuse of certain words and phrases (such as "OK”) or flicking the hair back from your face, which may detract from your ability Accepted draft 
to communicate with pupils effectively. You might find pupils spending more time counting how many times you say "OK” or flick your hair back than they spend listening to you. Your own habits and mannerisms are the focus of Task 8.4.

\section{Task 8.4 Your habits and mannerisms}

Ask another student teacher or your tutor to film you teaching one of your lessons. After the lesson observe the footage and try to detect any habits or mannerisms which could be hindering learning. Aim to reduce any such habits or mannerisms. Repeat the task at a later date to see if there is any difference. Record in your PDP how you reduced/eliminated the habit or mannerism.

\section{Awareness of the lesson climate}

A lesson with an effective learning environment has a positive climate. When we talk about the climate we are referring to the prevailing mood of the lesson. Pupils and their learning are placed at the centre of both the lesson planning and delivery. The lesson has a relaxed but purposeful atmosphere in which the pupils have a clear understanding of the ILOs. Pupils are expected to learn and to be on task (see Chapter 6), supported by a caring, enthusiastic teacher (see above). The teacher uses a positive teaching style, identifying and providing feedback on appropriate work, the positive reinforcement motivating pupils to learn and enhancing their self-esteem (see also Chapters 7 and 11 and Units 3.2 (Gervis and Capel) and 4.2 (Jepson and Walsh) in Capel, Leask and Turner, 2013). A positive climate in which specific feedback is provided about pupils' performance on a task, along with information about how to be more successful, in a way which is encouraging and supportive, is more likely to motivate pupils. Thus, much of the interaction in the class is positive, creating effective interpersonal relationships. A climate is not positive if it has all of the above, but no learning is taking place. You have, no doubt, experienced lessons in which there was a good atmosphere and pupils were 'busy, happy and good’ (Placek, 1983) but no learning was taking place.

\section{Being at ease in your teaching}

In a lesson with a positive climate you are likely to be at ease. If you are at ease, your pupils are likely to be so too. When pupils are at ease they are likely to be more confident, able to concentrate on the learning tasks and are more likely to behave appropriately. When you are at ease you are more likely to smile, conveying that you are confident and enjoying the work you are doing with the pupils. This can be aided by using humour effectively.

\section{Using humour}

As with other teaching skills, humour must be used appropriately. In the early stages of learning to teach you may wonder whether, when and how you should use humour. However, as you develop as a 
teacher, you should become more confident. Humour can be used to laugh at yourself when you have said or done something silly, to reassure a pupil who is anxious, to defuse a situation in which there is potential conflict, to laugh with pupils at something they find amusing (as long as that is appropriate for you as a teacher), for example, a hockey ball breaks in two and the pupils laugh about which part to use. Such scenarios reveal the more approachable and human side to your nature.

Although using humour well can be effective, using humour inappropriately can make lessons go terribly wrong. You must not use humour at a pupils' expense, for example to humiliate them through sarcasm. If you use humour too much pupils may perceive you as trying to be their friend, therefore you may become too familiar with pupils (see below; page ?). It may also make the lesson and pupils learning seem unimportant. Thus, effective use of humour can help you to establish a warm, caring, positive climate in your lessons, but if you do not use it effectively, it can destroy your working relationship with your pupils and undermine your authority. It should therefore be used with care and treated as a teaching skill to be developed as you do with any other skill. Task 8.5 asks you to focus on the lesson climate.

\section{Task 8.5 Lesson climate}

Observe two or three lessons, each taught by a different teacher. Focus on how the teacher establishes and maintains a positive lesson climate. Record examples of good practice in your PDP so that you can incorporate some of them into your own teaching, where appropriate.

\section{Awareness of why pupils misbehave}

It is important to be aware of possible internal and external situations and factors which may result in pupils misbehaving in your lesson. This provides information from which you can consider changes you can make to ensure there is a positive learning environment, reducing the likelihood of misbehaviour. Before continuing, reflect upon your past experiences and consider why pupils might misbehave in lessons by completing task 8.6.

\section{Task 8.6 Why pupils misbehave in lessons}

Try to think of at least 10 possible reasons why pupils might misbehave in lessons and then classify these under the headings below or create your own headings.

- Events happening outside of the classroom, at home, during break or lunch time;

- Organisation of the class and the learning environment;

- Tasks set within the lesson;

- The relationships between the pupils in your lesson;

- Verbal and non-verbal communication.

Compare your list with those of another student teacher. Store your list in your PDP for future reference. 
The interactions you have with pupils are based on your expectations, which in turn influence the way the pupil responds. If you expect pupils to misbehave, based on previous experience or reports from other teachers, they will probably fulfil your expectations. If you have high, but obtainable expectations, it is likely to lead to pupils performing well and behaving appropriately. Thus, expectations can be a self-fulfilling and therefore you should:

- have consistent, realistic yet high expectations of all pupils, and set obtainable, appropriate and challenging but achievable ILOs and tasks for them;

- focus on current performance rather than previous performance on an activity or task;

- avoid comparing one pupil's performance with that of other pupils;

- endeavour to motivate all pupils by providing positive, constructive feedback which helps the pupil to improve and raise standards;

See Unit 3.2 (Gervis and Capel) in Capel, Leask and Turner (2013) for further information about teacher expectations.

Likewise, if you use positive verbal communication you encourage positive behaviour. Strategies you may wish to try with your classes to develop a positive and effective learning relationship include:

- Make a casual comment rather than a reprimand: For example: 'I didn’t realise that we needed 3 basketballs in this game, can you make the changes please?'

- Framing questions: Rogers (2000, p.27) suggests using the 4 W's when framing questions to pupils about a behaviour problem:

- What's the problem specifically?

- What rule or right is being affected by this problem?

- Why do you think this problem is occurring?

- What can you do to fix the problem?

- It may also be useful to ask: how can I help?

- Use rule reminders: For example 'let's just recap that it is unsafe to chew gum in PE lessons, if anyone would like to put gum in the bin please use this opportunity.'

- If - then statements: These can be a great help in allowing pupils a little time to consider the consequences of their actions, e.g. if you do not follow the instructions given by the referee, I will ask you to leave the pitch to complete a 'rules awareness' task.

- Partial agreement: Agreement is an essential strategy for avoiding or resolving conflict. It means teachers not trying to have the last word, or asserting their power in a situation when a pupil disputes their judgment.

For example: Pupil, “I wasn’t talking, I was doing my work.”

Teacher, "OK, Maybe you were but now I want you to press on to finish the task". 


\section{A.R.T: RELATIONSHIPS}

This section looks at relationships: knowing pupils as individuals; communicating effectively; actions that promote positive interpersonal relationships between teacher and pupils, and between pupils; and understanding the impact of praise and rewards on behaviour and the learning environment.

\section{Building positive and respectful relationships}

Relationships play a key role in developing an effective learning environment and positive behaviour. Good relationships are at the heart of good behaviour. You need time and capacity to develop effective relationships with the pupils in your classes, which Rogers (2011) refers to as an 'establishment phase'. This usually occurs in the first few weeks of knowing a class and he contends that this largely determines the relationships developed from then on. He argues that $70 \%$ of pupils in any given class will work with a teacher providing they are engaging, confident and respectful and when a class meet a new teacher for the first time they will be looking at how the teacher deals with what he refers to as the 'early defining moments,' i.e. the first interactions with pupils that will determine the relationships dynamic of the class in the future. Non-verbal communication is important when developing relationships, for example, making eye contact with pupils, considering your facial expressions and varying your proximity to pupils, moving closer if you suspect a behaviour issue about to arise. You can also strategically ignore a specific behaviour if you believe the pupil is seeking your attention. Now complete task 8.7.

\section{Task 8.7 Early Defining Moments}

After you have taught your first lesson(s) with a number of classes, list the types of pupil behaviour that may be deemed 'defining moments' (both positive and challenging) in those early lessons with those classes. Now consider how you dealt with them and if in future you would repeat or change your actions. You may want to use table 8.1 to complete this task.

Table 8.1 'Defining moments' for developing relationships

\begin{tabular}{|c|c|c|}
\hline What was the pupil behaviour? & $\begin{array}{l}\text { What are your reflections upon } \\
\text { the actions you took? }\end{array}$ & $\begin{array}{l}\text { What have you learned from } \\
\text { this early defining moment? }\end{array}$ \\
\hline $\begin{array}{l}\text { E.g. In the first lesson, I } \\
\text { organised a starter activity which } \\
\text { involved pupil's checking prior } \\
\text { learning by writing their answers } \\
\text { to questions on the white board. }\end{array}$ & $\begin{array}{l}\text { I called over the small group of } \\
\text { pupils who were off task and } \\
\text { asked them firmly to return } \\
\text { equipment to the 'safe' area, and } \\
\text { to continue with the task. I }\end{array}$ & $\begin{array}{l}\text { I do not think that my initial } \\
\text { instructions and expectations } \\
\text { were clear enough; I gave pupils } \\
\text { too much time to complete the } \\
\text { activity. In future I need to ensure }\end{array}$ \\
\hline
\end{tabular}

Accepted draft 


\begin{tabular}{|c|c|c|}
\hline $\begin{array}{l}\text { This enabled pupils to engage in } \\
\text { thinking before all had arrived in } \\
\text { the sports hall. Some pupils did } \\
\text { not engage with this and were off } \\
\text { task using practical equipment in } \\
\text { the sports hall inappropriately. }\end{array}$ & $\begin{array}{l}\text { recapped the task and my } \\
\text { expectations and added } \\
\text { information about using } \\
\text { equipment safely and the loss of } \\
\text { valuable learning time. Pupils } \\
\text { responded by saying they had } \\
\text { completed the task. }\end{array}$ & $\begin{array}{l}\text { that pupils are fully aware of } \\
\text { what to do next if they believe a } \\
\text { task has been completed. I will } \\
\text { also ensure that timings of } \\
\text { activities are appropriate. }\end{array}$ \\
\hline & & \\
\hline & & \\
\hline & & \\
\hline & & \\
\hline
\end{tabular}

Store the table/list of both those actions you would repeat i.e. you felt supported the development of positive relationships and how (and why) you would change any future actions to lead to a better outcome in your PDP for use later.

\section{Knowing your pupils}

In establishing relationships it is important to learn pupil's names. If you learn pupils' names quickly, you send a message to pupils that you care about them as individuals and for their learning. However, it is not easy to learn pupils' names in PE lessons, as they are not sitting at desks. As a new teacher in the school you need to make a special effort to learn pupils' names. Many schools produce lists of photos of all pupils in a class. It can be very impressive to learn the names of the pupils before you meet them! You can learn names by talking to pupils at the beginning of the lesson when taking the register and at the end of the lesson. Teachers often use techniques such as asking pupils to say their names when they talk to them; set a goal of using pupils' names in, say, 50 per cent of interactions with them or set targets of learning, say, six names each lesson. However, it is difficult to hear what is being said in, for example, a swimming pool or when pupils are scattered in a large area, therefore you need to find techniques appropriate for the situation. Whatever technique you use it is important that as a student teacher you learn pupils’ names. Task 8.8 asks you to try techniques to learn pupils' names.

\section{Task 8.8 Learning pupils’ names}

As soon as you can, get a register of all pupils in your classes. Ask experienced PE teachers what techniques they use to learn names. Make a particular effort to learn the names of pupils as soon as Accepted draft 
you can. If one technique is not working, try another one until you have found a technique that works for you. Record in your PDP why a specific technique did or did not work.

In addition to learning names, you need to know pupils personally in order to build relationships with them. It is useful to know a little information about each pupil, e.g. something they are proud of, their interests as this provides a point of contact in interacting with them. It is also important to know about any particular needs, for example, high achievement, learning difficulties or emotional difficulties. The school can give you information and advice on considerations you should make when interacting with pupils.

You and your pupils must develop mutual respect for each other, accepting each other and valuing each other's viewpoints. All aspects of your teaching are important in showing you value pupils, including such aspects as questioning techniques. Asking open-ended questions, as well as developing pupils' higher order thinking (see, for example, Bloom, 1956; see also chapters 3 and 5 and the companion website http://www.???), are useful techniques for valuing pupils' contributions. A teacher may, for example, ask a question such as 'how can you get over a box without putting your feet on it'? If you only want and accept one possible answer 'a vault', you may discount an answer from a pupil who answers the question but does not give the answer you wanted. Hence, the pupil's answer is not valued and the pupil is not given the opportunity to make an effective contribution to the lesson. If you do only want one response, try not to totally discount an incorrect answer from a pupil, rather prompt the pupil to think again and guide them to give the correct answer. However, you need to think about whether the question is worded in the right way and whether you can ask questions which encourage more than one response.

Knowing the pupils in your class and how they react is vital in creating an appropriate climate for learning and to promote positive behaviour. Learning is multidimensional and often context dependent, e.g. pupils may respond differently in various activities, working with different groups, etc.

Within your lessons, what you say and do, your body language, verbal communication and expectations all impact upon the way pupils respond to you. You should show both verbally and nonverbally, that concern for pupils and their respective efforts are at the heart of the lesson. Task 8.9 is designed to help you consider the positive and negative aspects of your communication with pupils.

\section{Task 8.9 Positive and negative verbal communication}

What you say to pupils, why you say it, how and when you say it, have a direct influence on the climate you create in your lesson and on the learning of your. Record one of your lessons. Play the recording back and as you listen/watch it consider the following questions:

- Was your communication mostly positive or mostly negative?

- Were there any patterns to communication, for example, positive/negative feedback to some/all? Accepted draft 
positive about work but not about behaviour? different to able pupils compared to less able pupils? different to boys than to girls?

- How did your pupils respond to the communication?

Discuss with your tutor the pattern of your verbal communication, your pupils' response and the implications of this. Identify how you can increase the amount of positive communication, if appropriate.

Record your findings in your PDP. Try to put this into practice in your next lessons.

'You cannot control other people’s behaviour, only your own, yet you can influence and manage pupils' behaviour' (Whitehouse, 2014, p.174). Although you want to establish a good rapport with pupils, some student teachers on their initial school placement adopt a friendly approach to their pupils and then they have not been able to establish their authority. You must maintain your status as a teacher so that your authority is not undermined and so that pupils do not lose respect for you. If you establish a good relationship with your pupils you can exert your authority when you need to.

Siedentop (1991, p.132) identified the following components of good relationships:

- know your pupils;

- appreciate your pupils;

- acknowledge their efforts;

- be a careful listener;

- include pupils in decisions;

- make some concessions when appropriate;

- always show respect for pupils;

- show honesty and integrity;

- develop a sense of community, of belonging to the class.

Thus, it is important that you find a balance between controlling the class and placing a heavy reliance on punishment and being over friendly and familiar with pupils so that boundaries become blurred, potentially making some pupils feel socially excluded. If you establish a good relationship this will mean that you are establishing mutual decision making and equality within the classroom. That is not to say you should let pupils run riot but to support their part in the learning process. Roffey (2011, pp.103-104) lists a series of actions to support this.

- Greet pupils by name and smile so that you look pleased to see them;

- Show an interest; find out something about their life and ask the occasional question without interrogating them;

- Find something that you have in common, for example a team you both support or sport you both like playing;

- Find something that you can genuinely admire and comment positively on these qualities;

Accepted draft 
- Give regular positive feedback which is specific, genuine and brief;

- Let them know you believe they are worth the continued effort;

- Consistently show that their success, safety and well being is of concern to you;

- Model courtesy - open a door for them, say please and thank you;

- Tell the pupil what you enjoy about teaching them

(adapted from Roffey, 2011, pp.103-104).

As with all other aspects of your teaching you need to monitor your relationship with your pupils. Now complete task 8.10 .

\section{Task 8.10 Relationships with pupils}

Both observe the lesson of another teacher and ask your tutor to observe you towards the beginning and then at the end of the placement focusing on pupils' reactions to the teacher and the lesson. Make comments on and give examples for the following:

Do pupils get to class early? Do they change quickly? Are they enthusiastic?

Do pupils do things quickly and willingly?

Do pupils ask questions to enhance their learning?

Do pupils follow established rules and routines?

Do pupils treat the teacher and other pupils with respect?

Do pupils help one another without being prompted and feel positive about the class identity? Reflect on your observation of the teacher and on your tutor's observations of you. Discuss what these suggest about establishing positive interpersonal relationships with pupils. Reflect upon any progress you have made between the two observations. Keep the findings in your PDP to help you further develop your relationships with pupils in your classes.

\section{Rewards}

Pupils prefer to be praised rather than criticised. Praise can provide positive reinforcement, make pupils feel better, valued and work to achieve more in the lesson. You should use praise when pupils do something well, put effort into their work, show persistence and exhibit appropriate behaviours. Remember that it is important to praise effort as well as achievement. To be effective praise needs to be positive, encouraging, and specific. The general points to remember when using praise are not to over-praise as it becomes meaningless; make sure it is earned and sound and look as though you mean it. Rewarding effort/desirable behaviour and ignoring undesirable behaviour "rewards" and positively reinforces the behaviour you expect in lessons that have an effective learning environment and shifts the focus away from any bad behaviour (Kyriacou, 2009). It is important, therefore, to focus on the positive, not condoning the unacceptable but giving praise when appropriate and applying Accepted draft 
consequences which are appropriate for the behaviour when necessary. Task 8.11 helps you understand the praise that you use in lessons.

\section{Task 8.11 Use of praise}

Ask your tutor or another teacher to observe a lesson and identify your use of praise during the lesson. Identify such aspects as the balance between praise to individuals, groups or the whole class; for effort /achievement/behaviour. Who gets the praise, how often and why? Discuss how effective your use of praise was and what you can do in your next lesson to increase its effectiveness. Record this in your PDP to refer to in developing your use of praise in future lessons.

\section{A.R.T: THOUGHTFUL PLANNING}

This section looks at thoughtful planning in terms of how to use time effectively, ensuring all pupils are challenged and can achieve the intended learning, and the management of the working space.

\section{Thoughtful planning of time}

In a purposeful lesson a teacher must create as much time as possible for learning (see time on task in Chapter 6). You can achieve this by good organisation and management skills (see Chapter 6) and by establishing a good pace to the lesson. It is important when planning that you look for ways in which you can save time e.g. take the register whilst the pupils are changing. You should also make sure that the lesson starts as promptly as possible and that your organisation enables each task or lesson episode, including changing from one task or lesson episode to the next, to proceed smoothly and efficiently. Establishing a prompt and clear start to a lesson means that you are able to maximise lesson time and focus pupils attention on the learning environment from the outset, eliminating immediately any opportunities for disengagement that could lead to misbehaviour. You also create a sense of urgency in the lesson, encouraging pupils to do things quickly rather than dawdling, for example, pupils should jog to the outside space in which they are working, perhaps as part of the warm up, rather than walk along chatting to a friend. Organise pupils within the group to take responsibility for taking out equipment maybe on a rota, make them feel it is an important and responsible role. They should also have been set a task to start when they get to their activity space. Having a consistent approach to the start of every lesson means that pupils know what to expect and react quickly to instructions. Clear expectations helps create an effective learning environment and maximises your lesson time. Avoiding situations where pupils are waiting around for the teacher to organise them has a positive impact on learning and on behaviour as pupils are engaged in the lesson from the outset. You should not allow the pace of the lesson to slow, for example, by taking too long to explain what pupils are to do next or spending too much time on one task which could lead to 
boredom and possible disruption. When grouping pupils plan who will work with whom in advance if possible. Use a logical sequence of numbers for small-sided practices, such as 2-4-8, reorganising pupils from groups of 3 to pairs for example can take longer and can cause problems when breaking up friendship groups (See also chapter 6). Task 8.12 looks at purposefulness of a lesson.

\section{Task 8.12 Purposefulness of a lesson}

Observe two or three lessons taught by experienced teachers, focusing on the purposefulness of the lesson, for example, how long it takes for pupils to change for the lesson; what techniques the teacher uses and what is said to maintain a good pace to the lesson; how the teacher deals with unnecessary interruptions; how long pupils spend on each task; how long it takes to move from one task to another and how the teacher keeps this time to a minimum.

How do these compare with your own lessons? Ask another student teacher or your tutor to observe one or some of your lessons in relation to the same points. Do you need to change your practice to create a more purposeful lesson or plan more thoroughly for this to happen? Are there aspects of good practice you can adopt in your lessons? Identify what you need to do and try these out in your lessons. Record the teacher's and your own techniques in your PDP to refer to in planning further lessons.

\section{Thoughtful planning of learning for all}

A well organised approach to planning at three levels: detailed and well-structured lesson plans (short-term planning), units of work (medium-term planning) and, later, schemes of work (long-term planning) enables you to maximise opportunities for pupils to achieve the ILO’S. Careful planning should ensure that ILOs are clear and concise and when presented at the start of the lesson should give pupils an overview and understanding of the lesson focus and help to keep the pupils on task. Your lessons should be planned on a weekly basis with each lesson evaluation feeding into the planning of the next lesson, identifying any individual or personalised learning needs. It is better to over plan than under plan and it is important to critically reflect on your completed lessons and units to inform future planning. However, your lesson plans should be suitably flexible to allow for adaptations in response to pupil achievement and needs, using the unit of work as a guide or indicator. Capel and Blair (2013) note the danger of being too rigid in planning as this may lead to a routine or rigid approach to teaching that does not enable you to respond to the progress in learning needs of pupils in any one lesson. Planning is covered in Chapter 3; as well as in chapter 4 and 5 in Capel and Breckon (2014).

In order to allow all pupils to achieve success the obtainable, appropriate and challenging but achievable ILOs you set for pupils should be differentiated to meet the needs of different pupils and be meaningful to each individual. In England the inclusion statement for The National Curriculum (DfE, 2014a) states that teachers should set high expectations for every pupil, plan stretching work for pupils 
whose attainment is significantly above the expected standard, and plan in greater depth lessons for pupils with low levels of prior attainment and for those from disadvantaged backgrounds. You are also expected to use appropriate assessment to set ambitious targets for pupils. Inclusion is addressed in detail in Chapter 10.

Pupils' learning is affected by a number of factors, including their previous knowledge and experience of an activity, their individual needs and the learning situations which the teacher organises. An understanding of theories of learning, for example, Piaget (1962), Vygotsky (1962) and Bruner (1960), helps you to develop teaching tasks which are appropriate to pupils' learning needs and which actively engage them in their own learning. See Units 5.1 (Burton) and 5.2 (Lowe) on learning in Capel, Leask and Turner (2013) and try to apply the information to PE. You may also wish to consider the link between theories of learning and your teaching and learning strategies so that you can plan interesting and varied tasks to suit the range of different learning needs in any one class. Kolb’s (1984) Experiential Learning Cycle (cited in Jones and Barber, 2014, p.137) is also relevant here. We recommend adopting teaching and learning strategies that actively involve pupils in their own learning and which help them achieve a specific ILO (see also Chapter 13). Chapter 11 in Capel and Breckon (2014) provides some practical examples.

It is especially important to set obtainable, appropriate and challenging but achievable ILOs in PE because pupils' performance is on show, therefore failure in PE is particularly obvious. Physical actions and the success or otherwise of a pupil in accomplishing a task can be seen immediately by the rest of the class. ILOs and tasks that are too easy or too difficult will impact on pupils' achievement. Likewise, if a task or skill is too complex, or if it is not challenging enough, pupils may disengage. It is at the point that a pupil stops trying or 'goes off task' that behaviour issues can start. There is plenty of literature on teaching points for particular skills you might teach and, indeed, you include these in your lesson plans. An ability to 'read' what is happening during lessons and flexibility in adapting to changing circumstances is important (see chapter 4 on movement observation). Modifications to your planning as the lesson progresses - including teaching strategies, content, material, approach to pupil learning, may be needed to enhance an effective learning environment.

It is also important to plan for positive behaviour. This can be done through collaboration, consistency and consequences, i.e.

- Teacher/Pupils: A mutually agreed behaviour checklist is a starting point for lessons and classroom routines. Chapter 14 in Capel and Breckon (2014) offers some good advice and practical strategies for implementing these.

- Teacher/Teacher: School behaviour policies are written so that teachers have a consistent approach when dealing with negative behaviour and pupils are aware of the consequences of their actions. It is important therefore that you are aware of the policy and enforce it consistently.

- If you state a consequence, you must ensure that you follow through, e.g. if you warn a pupil 
that a consequence of their behaviour will mean that they will lose 5 minutes of their lunchtime, then you need to be prepared to action this.

\section{Thoughtful planning of the environment}

The working space is an important consideration when planning as the facilities and the equipment available in a particular space impact on pupil learning. The general appearance of the working space is an important factor in creating an effective learning environment. The space should be clean and tidy and convey a sense of care and attention to pupils and their learning. It is obviously hard to keep working spaces clean and tidy if a large number of groups and teachers are using the space or if a space is used as a multi-purpose facility, such as lunch served in the main school hall followed immediately by a dance or gymnastics lesson. In dance and gymnastics pupils are, for the most part, required to work in bare feet and oftentimes engage in floor work; thus, cleanliness and tidiness is of paramount importance for reasons of health and safety. Further, be mindful of potential hazards to your outdoor working spaces such as a long jump pit littered with drink cans and broken glass where pupils eat their lunch on the playing fields. This situation is made more difficult if a space is let to outside users. If you arrive for a lesson in a space that is unclean or untidy, it is worth cleaning or tidying it up before the lesson starts. You should also mention this to your tutor or Head of Department so that they can take steps to ensure that it does not happen again.

Each time you use a space you must check that it is safe (see also Chapter 12). This requires equipment to be well maintained and in good order. There should not be any equipment left lying around in a working space. Likewise, as your lesson progresses, you should make sure that spare equipment is put away safely and not left lying around. Also, ensure that equipment is put away properly after the lesson so that it is tidy and easily accessible and that the space and the changing rooms are left in a suitable state for the next group. Engage the pupils in looking after their learning environment in order to take responsibility for it.

You can enhance the space by using neat, tidy and well-presented visual displays, such as posters and notices. Ensure, as far as possible, that these are informative, current and meaningful to all pupils by, for example, changing the displays seasonally and featuring male and female role models from different cultural backgrounds. Where appropriate, you should select font text that all pupils can read (comic sans for those pupils with dyslexia). Posters are very useful in gymnasiums or sports halls for providing visual displays of skills. Examples of actions and balances are particularly useful when introducing partner work/sport acrobatics. Literacy skills can also be developed by displays of key words associated with an activity or lesson focus. Again, these need to be changed regularly as the activity or focus changes. There are several books and websites that you can refer to for advice on how to create good visual displays. All of these should help to create a positive feeling among pupils about the lesson and about the environment in which they are working as well as aiding pupil learning. 
Task 8.13 asks you to look at the PE spaces and task 8.14 (on the companion website www.???) identifies a range of strategies designed to support an effective learning environment for you to try out.

\section{Task 8.13 The PE spaces}

Are the PE facilities in your placement school attractive? Clean? Tidy? Well looked after? Do they invite participation? What can you learn that you can apply when you are in your own school? How can you create an attractive, motivating PE environment in your school? You might like to offer to create a display, for example on an activity or an event, and keep this information in your PDP for reference when you are in your first post.

\section{NON-VERBAL COMMUNICATION}

Throughout this chapter the importance of non-verbal communication in developing and maintaining an effective learning environment have been highlighted. Nonverbal communication is the process of communication through sending and receiving messages and cues between people which do not involve words or speech. Non verbal communication includes a range of things, including, for example, the way you present yourself, such as your appearance, gestures, posture, facial expression, habits and mannerisms, body language, touch, listening to pupils, distance, informal space around the body, the use of time and a clean and tidy workspace. It also includes the use of voice (see chapter 5). For example, eye contact is a form of non verbal communication which comprises actions of looking while talking and listening, frequency of glances, patterns of fixation, pupil dilation, and blink rate. Non-verbal signals are important for good communication, classroom management and control. Thus, it is important that you are aware of what non-verbal messages you are sending out yourself and through the learning environment and to be sure these are the messages you want to convey.

Non-verbal communication can have a considerable impact without any verbal communication in creating an effective learning environment and promoting positive behaviour, e.g. looking at a pupil slightly longer than you would normally communicates your awareness that they are talking or misbehaving. This may be sufficient to gain the pupil's attention. It can also have as great, if not greater, impact than verbal communication, depending on whether or not verbal and non-verbal signals match each other; for example, if you are sending a consistent message by praising someone and smiling and looking pleased or reprimanding them and looking stern and sounding firm, you are perceived as sincere. On the other hand, if you are smiling when reprimanding someone or looking bored when praising someone, you are sending conflicting messages that cause confusion and misunderstanding. Likewise, the appearance of the changing rooms, or posters on the wall, are a form of non verbal communication; if they are untidy, or the walls contain out of date lists or torn posters, 
for example, what message are you sending to pupils?

It is important to recognise the central role of non-verbal communication in all aspects of the A.R.T. model in developing an effective learning environment, as illustrated throughout this chapter.

\section{SUMMARY AND KEY POINTS}

A positive climate in your lessons helps to create an environment in which pupils can learn, supporting the other aspects of your teaching. In creating a positive climate it is important to realise that a wide range of messages are sent out in a variety of ways, including your self-presentation and the presentation of the working space, as well as the purposefulness of the lesson. In a purposeful lesson with a positive climate pupils are actively engaged in learning, motivated by obtainable, appropriate and challenging but achievable ILOs to enable them to experience success and enhance their self-esteem. Appropriate praise, feedback and guidance provide information and support to enhance further learning. This requires you to differentiate your material to cater for the needs of individual pupils (see Chapter 10) and to treat pupils in a way that shows you are interested in and care about them as individuals and about their progress. In order to create an effective learning environment, as an enthusiastic and committed teacher you should:

- plan and prepare each lesson thoroughly

- identify obtainable, appropriate and challenging but achievable ILOs for pupils, differentiating learning tasks to accommodate the needs of each individual pupil

- arrive early and provide a quick pace to the lesson, not allowing minor interruptions to disrupt the flow

- have a positive approach, praising pupils for effort or performance, giving specific, positive feedback whenever possible and encouraging pupils to achieve appropriate ILOs

- dress and act as though you are enthusiastic about, and participate in, physical activity yourself

- act as a positive role model in your skilful execution of movement skills wherever possible

- be aware of the impact all aspects of non verbal communication are having.

Check which requirements of your ITE you have addressed through this chapter.

\section{FURTHER READING}

Marland, M. (2002) The Craft of the Classroom, 3rd edn, London: Heinemann Educational.

A readable book that looks at classroom interaction.

Whitehouse, K. (2014) Teaching to promote positive behaviour, in S. Capel and P. Breckon (eds) A Practical Guide to Teaching Physical Education in the Secondary School, 2nd edn, Abingdon, Oxon: Routledge, pp.166-179.

Accepted draft 
This chapter looks at strategies to promote positive behaviour within the PE classroom.

Additional resources for this chapter are available on the companion website: http://www.???

Note: The authors would like to thank Peter Breckon, Susan Capel, Margaret Whitehead and Paula Zwozdiak-Myers for their contribution to previous editions of this chapter. 